\title{
Diabetes and poverty: A primer for resource poor countries
}

\author{
Altamash Shaikh, K. V. S. Hari Kumar ${ }^{1}$ \\ Department of Endocrinology, Saifee Hospital, Mumbai, Maharashtra, ${ }^{1}$ Department of Endocrinology, Army Hospital (R\&R), \\ New Delhi, India
}

\begin{abstract}
Diabetes mellitus is assuming pandemic proportions and is affecting both the developed and developing countries. India and China are the two most populous countries in the world that account for one-sixth of the world population. The prevalence of diabetes is also very common in these two countries next to that of the United States of America. The unique characteristics of diabetes in Southeast Asians include low body weight, high visceral fat, and also the increased insulin resistance. The developing nations have to grapple with the dual burden of the nutrient deficiency and excess states. The resources allocated for the health are often scarce and have to be utilized optimally in these places. The course and complications of diabetes also differ between the developed and developing nations. In this review, we describe the unique characteristics of diabetes in poor countries and also suggest certain remedial measures to improve the same.
\end{abstract}

Keywords: Diabetes mellitus, India, poverty, socioeconomic status

Address for correspondence: Dr. K. V. S. Hari Kumar, Department of Endocrinology, Army Hospital (R\&R), New Delhi, India.

E-mail: hariendo@rediffmail.com

Received: 30.07.2017, Accepted: 01.08.2017

\section{INTRODUCTION}

Economically, $80 \%$ of adults with diabetes live in resource poor countries which are low- to middle-income countries. Despite the immense advances in treatment and technology, still, we thrive to search for a complete cure of diabetes. In other words, management of diabetes can be expensive as it demands long-term care for the control of glucose and its complications. This burden increasing, as there is the rise in obesity and also the life expectancy. Poverty can be absolute or relative. Absolute poverty is when there is a lack of basic needs of food, clothing, and shelter (complete deprivation). Relative poverty is where the deprivation is such that may not allow for the job, leisure, and entertainment. The mechanisms by which poverty leads to diabetes are discussed beyond the usual ones such as lack of food, environmental toxins, stress, inflation, income, infection, or insurance cover.

\begin{tabular}{|l|l|}
\hline \multicolumn{2}{|c|}{ Access this article online } \\
\hline Quick Response Code: & Website: \\
\hline & www.joshd.net \\
\cline { 2 - 2 } & DOI: \\
& 10.4103/joshd.J_Soc_Health_ \\
\hline
\end{tabular}

\section{WHY LINK POVERTY AND DIABETES?}

In absolute terms poverty is defined as a daily income of $<2$ USD. ${ }^{[1]}$ People in the poorest nation have worst of the health. There is the evident lack of global pharmaceutical spending on health in low-income country $<1 \%$, middle (upper and middle each $<10 \%$ ) income country and high-income countries by around $80 \% .{ }^{[2]}$ However, poverty has its deleterious effect not only just in the underdeveloped but also in the developed countries, including the UK and USA. ${ }^{[3]} 12 \%$ of global health expenditure is spent on diabetes ( $\$ 673$ billion). By 2040, 1 adult in 10 (642 million) will have diabetes. ${ }^{[4]}$ Historically, India was the diabetes capital of the world, now being China. Geographically, 20\% of diabetes patients live in South East Asia. ${ }^{[5,6]}$ By 2040, the number will increase by $65 \%$ in South and Central America. Nearly

This is an open access journal, and articles are distributed under the terms of the Creative Commons Attribution-NonCommercial-ShareAlike 4.0 License, which allows others to remix, tweak, and build upon the work non-commercially, as long as appropriate credit is given and the new creations are licensed under the identical terms.

For reprints contact: reprints@medknow.com

How to cite this article: Shaikh A, Hari Kumar KVS. Diabetes and poverty: A primer for resource poor countries. J Soc Health Diabetes 2018;6:11-4. 
$37 \%$ of all adults with diabetes live in the Western Pacific region.

\section{DIABETES BECAUSE OF POVERTY?}

Many of the factors discussed here are inversely proportional to poverty and diabetes related complications. Education, occupation, income, insurance, the surrounding neighborhood, gender differences all have a link between poverty and diabetes. Patients with a background of lower socioeconomic status have been proven to have more incidences of diabetes. This is not only in resource poor countries but also in rich countries such as USA, UK, Australia, and Israel.

Low birthweight and fetal under-nutrition may have an effect on number of beta cells of the pancreas at the time of birth. Thus, seeds are sown and reap in adulthood as increase insulin secretion and hyperglycemia in later life. This is another reason as socioeconomic status is the main cause of diabetes distribution disproportionately in the population, the Barkers theory/hypothesis. ${ }^{[7]}$ Patients with lower socioeconomic status also are known to get more neuropathy, blindness, kidney disease, and other complications, including poor treatment adherence, poor follow-up, thus amounting to increase morbidity and mortality. Lower socioeconomic status patients either may delay or avoid going for treatment. ${ }^{[8]}$

\section{POVERTY BECAUSE OF DIABETES?}

When one takes treatment regularly and religiously, then only we should term it as long life! And not when usually as it is said do I need to take it life long!! The dictum is if you take treatment long time, then only life becomes long. Well, this translates, into the direct and indirect costs of managing diabetes. This can be both direct and indirect. The direct costs incurred in are due to monitoring, tablets, injections, medicines, devices for various complications of diabetes. All these would lead to less savings, less time for a job, lack of job depending on ensuing complications. Both together these costs may affect the national per capita income, of the already resource poor countries. This excludes the cost of undiagnosed diabetes and the cry of pain the diabetes patient undergoes. Seventy percent of patients in one study had treatment expenses incurred, increasing poverty in its double!! ${ }^{[8]}$ The maximum amount of resource is spent on drugs for diabetes, ${ }^{[9]}$ in some resource poor countries. However, most of these patients choose to handle hunger to handling disease, and end up in feeding self and children rather than treatment.

\section{CAN POOR NEIGHBORHOOD AFFECT DIABETES?}

Studies have proven earlier about the risks of poor neighborhoods and diabetes onset. In one such study, people were $38 \%$ less likely to develop diabetes if neighborhoods were well resourced with healthy food and exercise. ${ }^{[10]}$ lack of grounds, gardens, groceries, greenery, amounts to poor walkability, and poor motivation for physical activity. This point in the treatment of diabetes is important, as we, usually think of a medical issue only in the management, however we should also think in line of the neighborhood and poverty as additional causes of preventable factors for diabetes.

\section{URBAN POOR, RURAL POOR AND DIABETES}

Difficulties faced by the urban poor are, (1) Patient related: Familial and financial constraints, (2) Doctor related: Attitude and communication related and (3) Health care system related. ${ }^{[11]}$ This indicates the role of poverty even in the urban areas of cities with better health facilities than rural areas. The prevalence of diabetes is more in rural areas. Body mass index, age, gender, and income was associated with more prevalence. The issues are those of distant hospitals and insurances that are lacking for the rural patients to take benefit from. In rural areas, not only access to medical facilities, availability of fruits and vegetables may be an issue, as they would be more inclined to sell them to make their daily wages and income to feed the family. For all above factors, patients in rural areas may be away from the real benefits of treatment medications, and advances in management of diabetes and complications.

\section{CHILDHOOD POVERTY AND DIABETES}

Childhood poverty may influence development of various diseases such as, respiratory disease, diabetes, psychiatric disorders, and some cancers in addition to the poor economy for resource poor countries. Economic status of the child and family during this period affects adult onset of diabetes, even if later economic status is improved. ${ }^{[3]}$ Childhood poverty may be both absolute and relative. It may result in adulthood diabetes as in one study, there was a $80 \%$ more chance of having diabetes in adulthood, in children growing from lower socioeconomic status, compared to higher socioeconomic status. It was $50 \%$ higher even after correcting factors such as income, job, height, weight, alcohol, smoking, activity, and education completed in adulthood. ${ }^{[12]}$ Manual worker at childhood only increases chances of diabetes by $55 \%$, whereas being a manual worker at childhood and adulthood both increased to $241 \%{ }^{[13]}$ 


\section{SEX DIFFERENCES IN DIABETES AND POVERTY}

Gendered nature of diabetes care is an important hindrance in the community in resource poor countries. Women empowerment is an integral part of treating diabetes, whether rich or poor. It has its importance in the treatment of not only the lady with diabetes but also any other member having diabetes in the family. Women in lower socioeconomic status are involved in cooking and caring for the family, not involved in employment or outdoor activities, making them less susceptible to medical facilities, by not moving out of the house, be it for a walk or a distant medical care. Women should be the first point of contact for family therapy and diabetes, ${ }^{[14]}$ this shall reduce the familial constraints in the poor and facilitate diabetes management. There is 4 times the risk of developing diabetes, in the lowest third socioeconomic status group compared to women in upper socioeconomic status, in Peru. ${ }^{[15]}$

On the other hand, women also face issues with intergenerational conflicts in the treatment, for example, between mother in law and daughter in law. ${ }^{[1]}$ This may limit the needed amount of care for the elderly and others. Of the several studies, Peruvian men had 2 increased risk of developing high fasting glucose than upper socioeconomic status men. ${ }^{[15]}$ One different point in men poverty and diabetes is that in some studies men had positive mood, energy and well-being than women, ${ }^{[16]}$ thus making their diabetes treatment better in time.

\section{TEACHING PATIENT, TRAINING FAMILY, AND TREATING POVERTY}

Education of the patient and family members stands prominent part of treating the poor patient. Evidence for that comes from certain studies, belonging to low, middle and low income people. In a Mexican study, looking for changes in diet and activity, patients were called for education along with invitation to family members. It showed improvements in dietary and exercise patterns of the patients. ${ }^{[17]}$ for the resource poor countries and the poor patient, not only education for diet or exercise, but also for complications and insulin education, family holds a good great window to aid in the management of diabetes. ${ }^{[14]}$ Breaching the gap between doctor/educator and patients from resource poor countries by educating is important than just putting a blame on the patient.

\section{HEALTH IMPLICATIONS}

Large proportions of death and disability due to diabetes are preventable, given proper self-care, patient and family education, better control of complications. ${ }^{[14]}$ Diabetes awareness, education, primary prevention, and family therapy are a few important steps to be taken for the reduction of the burden of poverty and diabetes. Moving into a low poverty zone from a high poverty zone is beneficial in terms of changes in the selection of foods and perception toward diabetes. In one study, this helped in reduction of glycated hemoglobin by $25 \%$. ${ }^{[18]}$

Of the noncommunicable diseases, diabetes still is deadly for the poorest of developed countries. Thus, poverty has effects beyond resource poor countries. Patients in resource poor countries suffer disproportionately due to hyperglycemia and related complications than others! Clinicians should emphasize on how to apply interventions in patients in resource poor countries. We need to understand the consequences of poverty, and how it affects socially. Every rich person has seen poverty in theirs front in the form of their employed personnel, be it a maid or a servant.

\section{CONCLUSIONS}

Prevention of risk factors of diabetes effectively at lower socioeconomic status needs to be implemented urgently. The availability of primary care, medicines, education, healthy food, and surroundings are needed to be implied in the national policies of resource poor countries, to make management of diabetes in such areas a success! Preventing and treating diabetes in resource poor countries itself will save a lot, and diverting health an economy to resource rich country.

\section{Financial support and sponsorship}

Nil.

\section{Conflicts of interest}

There are no conflicts of interest.

\section{REFERENCES}

1. Available from: http://www.who.int/topics/poverty/en/. [Last accessed on 2017 Jul 25].

2. Lu Y, Hernandez P, Abegunde D, Edejer T. The World Medicines Situation 2011. Medicine Expenditures. $3^{\text {rd }}$ Edition, Geneva: WHO, p. 32. Accessed from: http://apps.who.int/medicinedocs/documents/ s18767en/s18767en.pdf. [Last accessed on 2017 Jul 25].

3. Innocenti Research Centre. The Child Care Transition: A League Table of Early Childhood Education and Care in Economically Advanced Countries. Florence: Innocenti Research Centre; 2008.

4. Available from: http://www.diabetesatlas.org. [Last accessed on 2017 Jul 25].

5. International Diabetes Federation. IDF Diabetes Atlas. $5^{\text {th }}$ ed. Brussels: International Diabetes Federation; 2015.

6. World Health Organization. Global Report on Diabetes. Geneva: WHO; 2016. 
7. Hales CN, Barker DJ. Type 2 (non-insulin-dependent) diabetes mellitus: The thrifty phenotype hypothesis. Diabetologia 1992;35:595-601.

8. Bhojani U, Thriveni B, Devadasan R, Munegowda C, Devadasan N, Kolsteren $\mathrm{P}$, et al. Out-of-pocket healthcare payments on chronic conditions impoverish urban poor in Bangalore, India. BMC Public Health 2012;12:990.

9. Ghosh S. Catastrophic payments and impoverishment due to out-of-pocket health spending. Econ Polit Wkly 2011;xlvi: 63-70.

10. Auchincloss AH, Diez Roux AV, Mujahid MS, Shen M, Bertoni AG, Carnethon MR. Neighborhood resources for physical activity and healthy foods and incidence of type 2 diabetes mellitus: The multi-ethnic study of Atherosclerosis. Arch Intern Med 2009;169:1698-704.

11. Bhojani U, Mishra A, Amruthavalli S, Devadasan N, Kolsteren P, De Henauw $\mathrm{S}$, et al. Constraints faced by urban poor in managing diabetes care: Patients' perspectives from South India. Glob Health Action 2013;6:22258.

12. Maty SC, Lynch JW, Raghunathan TE, Kaplan GA. Childhood socioeconomic position, gender, adult body mass index, and incidence of type 2 diabetes mellitus over 34 years in the Alameda county study. Am J Public Health 2008;98:1486-94.
13. Lawlor DA, Smith GD, Ebrahim S. Association between childhood socioeconomic status and coronary heart disease risk among postmenopausal women: Findings from the British Women's Heart and Health Study. Am J Public Health 2004;94:1386-92.

14. Altamash S. Family therapy in diabetes mellitus. Indian J Endocrinol Metab 2013;17 Suppl 1:S292-4.

15. Goldstein J, Jacoby E, del Aguila R, Lopez A. Poverty is a predictor of non-communicable disease among adults in Peruvian cities. Prev Med 2005;41:800-6.

16. Shobhana R, Rama Rao P, Lavanya A, Padma C, Vijay V, Ramachandran A. Quality of life and diabetes integration among subjects with type 2 diabetes. J Assoc Physicians India 2003;51: 363-5.

17. Albarran NB, Ballesteros MN, Morales GG, Ortega MI. Dietary behavior and type 2 diabetes care. Patient Educ Couns 2006;61: 191-9.

18. Orr L, Fein J, Jacob R, Beecroft E, Sanbonmatsu L, Katz L. Moving to opportunity for fair housing demon-stration program interim impacts evaluation. Washington, DC: US Department of Housing and Urban Development; 2003. 